San Jose State University

SJSU ScholarWorks

Faculty Publications

Psychology

$1-1-2005$

\title{
Behavioral and psychological symptoms of dementia: The effects of physical activity at adult day service centers
}

\author{
Erin L. Woodhead \\ San Jose State University, erin.woodhead@sjsu.edu
}

S. H. Zarit

Pennsylvania State University

E. R. Braungart

Pennsylvania State University

M. J. Rovine

Pennsylvania State University

E. E. Femia

Pennsylvania State University

Follow this and additional works at: https://scholarworks.sjsu.edu/psych_pub

Part of the Psychology Commons

\section{Recommended Citation}

Erin L. Woodhead, S. H. Zarit, E. R. Braungart, M. J. Rovine, and E. E. Femia. "Behavioral and psychological symptoms of dementia: The effects of physical activity at adult day service centers" American Journal of Alzheimer's Disease and Other Dementias (2005): 171-179. https://doi.org/10.1177/

153331750502000314

This Article is brought to you for free and open access by the Psychology at SJSU ScholarWorks. It has been accepted for inclusion in Faculty Publications by an authorized administrator of SJSU ScholarWorks. For more information, please contact scholarworks@sjsu.edu. 
Running Head: PHYSICAL ACTIVITY

Behavioral and Psychological Symptoms of Dementia:

The Effects of Physical Activity at Adult Day Service Centers

Erin L. Woodhead, B.S. ${ }^{1}$

Steven H. Zarit, Ph.D. ${ }^{2}$

Elizabeth R. Braungart, M.S. ${ }^{2}$

Michael R. Rovine, Ph.D. ${ }^{2}$

Elia E. Femia, Ph.D. ${ }^{2}$

${ }^{1}$ West Virginia University, ${ }^{2}$ The Pennsylvania State University

Dept. of Human Development and Family Studies, Henderson S-211, University Park,

PA 16802

(814) $865-5260$

FAX: (814) 863-7963

Direct Correspondence To:

Erin Woodhead

Department of Psychology

53 Campus Drive

1124 Life Sciences Building

Morgantown, WV 26506-6040

(304) 376-3338

ewoodhea@mix.wvu.edu 


\begin{abstract}
Adult day services (ADS) are an increasingly popular option for caregivers of people with dementia, but there is little research on the effects of activities on the behavior and mood of the client. This study examines participation by 94 individuals in different types of adult day care activities, and their association with changes in behavior and psychological symptoms of dementia (BPSD) for the client during a three month span. Three domains of BPSD were examined: restless behaviors, mood behaviors, and positive behaviors. Using growth curve modeling, results show that the restless and mood behavior domains, on average, were stable over three months, while positive behaviors increased. For all three behavior domains there were individual differences in average level of BPSD. Average rate of change for individuals also varied from the mean for restless and mood behaviors. Physical activities, social activities, engaging activities, and watching and listening activities, along with a day care dosage variable were used as covariates to explain these individual differences in change. Engaging activities explained some of the individual variance for restless behaviors; as individuals increased one increment in engaging activities, they had fewer restless behavior problems over time. These results suggest that some features of programming may be related to improvements in restless behavior.
\end{abstract}


Behavioral and psychological symptoms of dementia (BPSD) may be the most difficult and challenging stressors faced by caregivers. BPSD include both psychological (e.g., problems with mood, anxiety, or paranoia), and behavioral components (e.g., activities of daily living; Zarit et al., 1998). BPSD is stressful not only for family caregivers, who must cope with difficult and unpredictable behavioral disturbances, but also for paid caregivers.

Among community dwelling older adults with dementia, prevalence rates of 45 to $50 \%$ were found for verbal-vocal agitation, 8 to $30 \%$ for aggression, 3 to $30 \%$ for wandering, and 12 to $32 \%$ for crying (Patterson \& Bolger, 1994; Teri et al., 1992). Among those attending adult day service centers (ADS), affective disorders were most prevalent, along with verbal-vocal agitation, misplacing things, and refusing to cooperate (Teresi et al., 1997). Improved treatment of BPSD can reduce the pressure on family and paid caregivers, as well as create opportunities for better interactions with the person with dementia.

One promising approach for improving well-being among people with dementia and reducing BPSD is through activities. Activities have been at the core of therapeutic programs in community and institutional settings. At ADS, activities and social experiences are used to create immediate pleasure, restore dignity to the client, provide meaningful tasks, restore lost social roles, and build friendship (Mace, 1987). Specifically, engaging people in meaningful and enjoyable activities may lead to a reduction in restlessness, depressive behaviors and other dementia-related behavior problems. This engagement can also alleviate feelings of loneliness and boredom that can contribute to inappropriate displays of verbal agitation and other problem behaviors 
such as repetitive mannerisms (Cohen-Mansfield et al., 1995). Activities provided by ADS programs provide this structure to the person with dementia, thereby reducing some common problematic behaviors.

An overriding issue when evaluating ADS activities is Lawton's idea of personenvironment match (Parmelee \& Lawton, 1990). The concept here is that performance and adaptation are maximized when environmental characteristics match with the individual's needs and deficits. In the case of people with dementia, if they are placed in an unfamiliar environment (the adult day care center), they may perceive a loss of control if they are unable to competently perform the activities provided for them. This lack of fit could lead to an increase in BPSD. Conversely, where there is a good match between environmental demands and client abilities, the person with dementia may become more engaged in activities, decreasing restless and disruptive behavior (Parmelee \& Lawton, 1990).

Many ADS programs offer formal exercise for those who attend. Several researchers have examined the effects of exercise on older adults on non-ADS samples (Brandon et al., 2004; Blumenthal \& Gullete, 2002). As these studies have demonstrated, older adults can experience many benefits from exercise. These include improved cardiovascular fitness and improved flexibility and strength, which potentially assist the elderly client in performing activities of daily living (Thompson \& Born, 1999). Williams and Lord (1997) showed that elderly women in an exercise program experienced improvements in general fitness, health, sociability, mood and outlook compared to a control group who showed little change in each of the above measures. Additionally, physical exercise may also improve appetite, digestion, respiration, and 
sleep patterns of the elderly (Mace, 1987). The mastery of physical activities may also boost one's sense of achievement and self-efficacy, thereby improving mood (Yeung, 1996).

Exercise may be a useful short-term strategy for alleviating psychological distress, in all age groups, and across all levels of disability and/or physical handicap (Yeung, 1996). Few recent studies, however, have focused specifically on the effects of exercise among people with dementia (e.g., Bonner \& Cousins, 1996; Beck et al., 1992). One exception to this is a recent large-scale randomized trial by Teri and colleagues (2003). This study found that when caregivers engaged their relative with dementia in regular exercise and also used problem solving to manage behavior problems, the person with dementia experienced decreases in depressive symptoms and improved functional performance, compared to control subjects. The potential difficulty with using exercise with dementia patients, however, is in finding a critical balance between a level that exceeds participants' abilities, which may cause anxiety and frustration, and levels that are too simple and lead to boredom and disengagement. Both ends of the spectrum may cause an excess of BPSD in an adult day care client with dementia.

In addition to the benefits received by the day care participant in a given physical activity, the caregiver of the person with dementia may also experience some of these positive aspects of exercise. When there is a lack of daytime activities that engage the elderly person, many care providers find themselves with a relative/care receiver who sleeps during much of the day, or who engages in problem behaviors (Thompson \& Born, 1999). If the person with dementia is engaged in physical activities during the day at 
adult day care, the caregiver may potentially experience fewer problem behaviors from their relative upon return from day care (Femia, 2004).

Cognitive stimulation has been used much more often with dementia patients with varying results (Woods, 1996). Given the cognitive limitations of people with dementia, and the often uneven functioning in different domains from one person to the next, or even over time for the same person, it may be even more difficult to find a balance in cognitive activities between overly demanding and too simple. Research would suggest that although cognitive exercises may have benefits for people with dementia, they also have the potential to reinforce inadequacy for those clients whose memory and motor skills are at a low level (Mace, 1987).

Activities to foster social interaction represent another component of ADS and other activity programs. Going to a congregate setting by itself provides new social stimulation for people with dementia, who often stay at home for long periods of time, interacting mainly with their primary caregiver. Social activities can draw upon wellrehearsed social skills that are maintained relatively well in at least some participants.

This study examines the relation of four types of activities-engaging, social, physical and watching and listening activities - and whether they affect BPSD of ADS users over a 3-month period. Taking into account the studies discussed above, we hypothesize that participation in physical activities will significantly reduce restless and mood behaviors, and significantly increase positive behaviors.

\section{Methods}

\section{$\underline{\text { Participants }}$}


The participants were drawn from a larger study evaluating the effects of ADS on family caregivers and people with dementia. To be included in the study, the care receiver must have had a diagnosis of dementia, and a score on the Mini-Mental State Exam (MMSE; Folstein, Folstein, \& McHugh, 1975) of less than 24, indicating significant cognitive impairment. At the time of recruitment they must have been enrolling in adult day services, and once enrolled, they had to have maintained attendance at day care for a minimum of four hours a day, twice a week. For this study, care receivers also had to be living in the community in the same home as his or her primary caregiver. The sample ( $\mathrm{n}=94)$ had an average age of 79.6 , and an average score on the MMSE of 14.6. Information on the demographic variables for both the caregiver and the person with dementia is provided in Table 1.

\section{INSERT TABLE 1 ABOUT HERE}

\section{$\underline{\text { Design and Procedures }}$}

ADS program staff at the 23 day care sites referred potential participants for the current study to research investigators, who contacted the primary caregiver and conducted a series of in-person and telephone interviews. Once enrolled in the study, research investigators asked ADS staff to collect background information and behavioral data on the participants over a 1-year period of time. The behavioral data were collected on two consecutive days each month, at baseline, and then at one, two, and three months post-baseline, for a total of eight data points. The two baseline days were collected on days within the client's first week of attendance, before the effects of day care activities were expected to have an effect on levels of BPSD. In order to be included in these analyses, individuals had to have at least four of the eight data points over the three 
month observation period. For final analyses, the two consecutive days of data collection were averaged to form one data point for each month, for a total of 4 data points per participant.

Staff received training at the start of the study in the use of the measures, and also received a manual to help with questions in completing the measures. Investigators were available via telephone to answer questions that might come up about the measures. $\underline{\text { Measures }}$

Behavioral symptoms of dementia were measured with the Daily Record of Behavior (DRB; Femia, Leitsch, Zarit, \& Stephens, 2001). The DRB was developed for the study to measure specific occurrences of behaviors during the selected period of the day. It was designed to be used by both caregivers and staff at adult day care, however for the current analyses, only the version used by ADS staff will be analyzed. Items for the DRB were drawn from existing scales of behavior problems and were selected for providing a clear and specific description of the behavior so that it could be rated by an untrained respondent. Although the DRB is a newer scale, it has demonstrated reliability. Past analyses of the DRB have shown significant agreement across day-to-day comparisons and daily to weekly comparisons (Leitsch et al, 2000). Agreement has also been shown between the caregiver version of the DRB and the version used by the ADS staff (Wilson et al., 2000). Additionally, the rank order of the behavior problems was similar across both the caregiver DRB and a weekly record of behavior problems (Femia, Leitsch, Zarit, \& Stephens, 2000).

In the DRB, ADS staff use a set of structured questions to report the occurrence of 37 behaviors during the time period in which the client attended day care. The behaviors 
fall into 9 categories: behavioral disturbances while eating, problems associated with toileting, restless behaviors, mood and anxiety behaviors, napping, disruptive behaviors, memory problems, reality problems, and positive behaviors. For the purpose of this study, the domains of positive behaviors, mood problems, and restless behaviors were selected for analysis. A sample of the DRB form is provided in Figure 1.

\section{INSERT FIGURE 1 ABOUT HERE}

These three domains, which included 15 items from the original DRB scale, were chosen because they were hypothesized to be most responsive to day care activities.

For each behavior, the designated day care staff person indicated if a behavior occurred during the day care day, how many times the behavior occurred, and how long the behavior lasted. The staff person also rated how stressful he/she found the behavior, using a four-point scale that ranged from not at all (value of 1) to very (value of 5). This stress rating was not obtained for the positive behaviors. For this study, we focus on the frequency and duration of the behavior problems.

In addition to reporting behavioral symptoms in the DRB, staff identified the organized day care activities that occurred on the same days that the behavior problems were assessed. They were also instructed to attach a copy of that month's activity calendar. To report activities, staff completed a checklist of 19 activities commonly offered by ADS programs and indicated whether the client with dementia participated in these activities. The checklist was developed specifically for the current study by reviewing activity calendars from several of the participating ADS programs in a pilot study. For this activity measure, staff indicated if an activity had occurred that day, how long it went on, and how long the ADS client engaged in that behavior. 
Five graduate and undergraduate raters sorted the activities into categories until there was a high degree of agreement (over 90\%) about which category an activity belonged in. Categories were: physical, social, engaging, or watching and listening activities. The distinction between engaging activities and watching and listening activities lies in the level of involvement required by the participants. Activities that required active involvement by the participant were placed in the engaging activities category. Conversely, activities that involved more passive engagement by the participant were placed in the watching and listening activities category. The categories and items are summarized in Table 2.

\section{INSERT TABLE 2 ABOUT HERE}

Analyses

Prior to running our analyses, the activity variables were recoded in order to identify different participation levels. Using the section of the activity checklist that indicated how engaged the client was in the activity, the participation in physical, social, engaging, and watching and listening activities were split into three separate percentile groups, to form new variables coded as high, medium, or low participation.

Growth curve modeling was used to examine changes in restlessness, mood, and positive behavior over time. For the first step in the analyses, a series of models were tested separately for each behavior domain to determine which model was the best-fitting one. The first model that was run in the analyses was a linear curve model. This model was then compared to a quadratic curve model. Using chi-square difference tests to compare these alternative nested models (e.g., Bollen, 1998), the best-fitting model was determined for each behavior domain. From the best-fitting models for each of the three 
behavior domains, the fixed and random effects of initial level, slope, and quadratic slope (for restless behaviors only) were tested for significance.

For the second step of the analysis process, these best-fitting models were re-run with five covariates included. The covariates were the four types of day care activities (physical, social, engaging, watching and listening, recoded as low, medium, and high participation), as well as a day care dosage variable which measured the number of days that the participant attended adult day services across the three months. In this step, it was determined if these five variables were significantly related to the fixed and random effects of intercept and slope for each of the three behavior domains. We used the statistical package Mplus (Muthén \& Muthén, 2000) to run our statistical models.

\section{Results}

The best-fitting model for restless behavior problems was a quadratic curve model. For mood behavior problems and positive behaviors, the best-fitting model for each was a linear curve model. The chi-square values and fit statistics for each model are presented in Table 3.

\section{INSERT TABLE 3 ABOUT HERE}

Significance tests of the parameter estimates for fixed and random effects from these best-fitting models revealed several statistically significant findings. The fixed effect of intercept was significant for all three behavior domains, indicating that the average initial levels of restless, mood, and positive behaviors were all significantly different from zero at baseline. The fixed effect of linear slope was not significant for restless or mood behaviors, indicating that, on average, there was no change in the occurrence of these behaviors over three months. A significant and positive $(>0)$ fixed effect for positive 
behaviors, however, indicated that positive behaviors significantly increased over three months.

For the random effects, variance of the random intercepts was significant for all of the behavior domains tested. This indicates that there is significant variability in participants' baseline levels of restless, mood, and positive behaviors. Additionally, for restless and mood behaviors, the variance of the random slopes was significant indicating that the individual rates of changes significantly varied around the average rate of change. For positive behaviors, however, the random effect for slope was not significant, indicating that individuals' slopes display patterns of change that are similar to that which is displayed by the group's mean pattern of change. This demonstrates that the increase in positive behaviors over 3 months as displayed by the mean was also a typical pattern for participants' individual slopes. These findings are presented in Table 4.

\section{INSERT TABLE 4 ABOUT HERE}

In order to account for individuals' variability about the mean as described by the significant random effects, the four activity variables and the day care dosage variable were included in separate models as covariates. The results from these models are shown in Table 5.

\section{INSERT TABLE 5 ABOUT HERE}

For restless and mood behaviors, none of the covariates predicting the intercepts were significant, indicating that the amount of adult day care usage and the amount of participation in physical, social, engaging, or watching/listening activities at day care did not predict individual variability about the mean for baseline levels of restless or mood behaviors. For positive behaviors, social activity was the only significant covariate 
predicting intercept. The positive value of this parameter estimate indicates that individuals who had participated in more social activities at day care had higher levels of positive behaviors at baseline.

Two covariates were significantly related to the individual variability in linear slopes of specific behaviors. Engaging activities had a significant association with the variability in linear slope for restless behavior problems and had a negative value for the estimate. These results indicate that individuals who participated in more engaging activities at day care showed significantly more decline in restless behavior problems over three months as compared to individuals with lower amounts of engaging activity.

The second variable that was related to individual variability in linear slope was the day care dosage variable. For restless and mood behaviors, significant slope effects with positive values indicated that participants attending more days of day care had an increased slope for these behaviors over three months as compared to those who attended fewer days. That is, people who attended more day care increased in their restless and mood behaviors to a greater extent than those who attended less day care. For positive behaviors, there was no variability in the slope that could be explained by the covariates.

\section{Discussion}

This study examined the hypothesis that physical activities at adult day service centers have the greatest effect on reducing restless and mood behaviors, and increasing positive behaviors for people with dementia, over a three month period. This initial hypothesis was not supported in the analyses. We did, however, find some evidence that activities at adult day services had positive benefits for clients. Positive behaviors increased for all participants across the three month period. We also found that 
individuals who are involved in more engaging activities decreased in restless behavior problems.

In addition to the above findings, our results also indicated that for restless and mood behaviors, participants who attended more day care had a significant increase in these behavior domains. It is possible that this unexpected finding for the dosage variable is due to a selection effect. For instance, participants who attend attended day care more frequently may have had larger amounts of restless and mood behavior problems at baseline, and hence, may be more resistant to day care programming, at least for the first 3 months of day care attendance.

It is also important, however, to note the modest magnitude of the effects, both for the significant findings relating to day care dosage and for the findings related to participation in engaging activities. That is, although these findings are significant, even those participants with the highest level of day care dosage and those with the highest level of participation in engaging activities were not experiencing dramatic increases or decreases in their behavior over time. In other words, although for both the day care dosage and participation in engaging activities variables the values of the slopes at low, medium, and high groups are significantly different from each other, participants' slope levels stayed close to zero even for those participants in the highest dosage group and those in the highest participation in engaging activities group. This indicates that even though change was significant, the magnitude of change was relatively modest.

Although somewhat surprising, these findings point to how adult day care may influence behavior patterns among people with dementia. The increase in positive activities among participants is noteworthy. In contrast to low levels of functional 
activity typical of middle stage dementia patients at home, people in day care have a structured day that keeps them active and involved. These activities may help bring out more socially-appropriate and positive behaviors. In a similar way, engaging behaviors may lead in a direct way to diminish restless, aimless activity that may have stemmed from boredom. Engaging activities encompass those activities that the person with dementia can individually tailor to his/her level of desired participation. The potential benefit of individually tailored activities is supported by Opie, Doyle, and O'Connor (2002), who demonstrated support for multidisciplinary interventions tailored to the individual for reducing the frequency and severity of disruptive behaviors in those with dementia.

The hypothesis about the effects of physical activity on behavior problems was not supported. Although we were provided information by the ADS staff about whether physical activities were offered, we did not receive information about the intensity of the exercise. It is possible that activities were not challenging enough to have an impact on behavior problems. Some dementia patients are able to engage in high levels of physical activity, for instance, walking long distances. For them, relatively basic physical movements, such as a knee pull exercise, may be too minimal to have an effect.

There are limitations to the design of the current study. One limitation is the lack of a control group of participants not attending adult day services. The findings do not address whether there are changes in behavior as a result of attending adult day services, but rather that there are some relationships between the types of activities at day care and behavior problems. It remains to be determined if behavior problems at day care change in a systematic way relative to people not attending day care. 
Another limitation worth noting is the reliance on self-reports of BPSD and participation in activities from the ADS staff. Direct observation of BPSD by research staff, of the physical intensity of activities, and of the levels of cognitive engagement initiated by activities would be very useful for determining possible effects on behavior and mood.

Future work on studying the effects of activities may want to consider a more individualized approach, and consider that levels of optimal activity may differ among clients. When observing exercise programs, for example, it may be that the dosage of exercise producing the greatest reduction in BPSD varies from person to person, and that exercise activities that take this into consideration are more effective than those which administer the same amount of activity to all clients.

The present study used the approach of dividing activities into categories that, from a theoretical viewpoint, might have differential effects on specific BPSD. Another potential limitation to this study is that the categorization of behaviors used here was not ideal. There has been little prior research on specific types of activity programming at adult day service centers. Many of the articles on this topic focus on components of communication that are beneficial to Alzheimer's patients, such as prompting, cues, and individual praise (Thompson \& Born, 1999), or on improving physical problems such as appetite and respiration (Mace, 1987). In order to better understand the positive outcomes related to activities at day care, more work is needed to determine the best ways of categorizing and measuring activities. 


\section{References}

1. Zarit, S.H., Stephens, M.P., Townsend, A., \& Greene, R. (1998). Stress reduction for caregivers: Effects of adult day care use. Journal of Gerontology: Social Sciences, 53, S267-S277.

2. Patterson, M.P., \& Bolger, J.P. (1994). Assessment of behavioral symptoms in alzheimer's disease. Journal of Alzheimer's Disease and Associated Disorders, 8 , 3-20.

3. Teri, L., Rabins, P., Whitehouse, P., Berg, L., Reisberg, B., Sunderland, T., Eichelman, B., \& Phelps, C. (1992). Management of behavior disturbance in Alzheimer's disease: Current knowledge and future directions. Journal of Alzheimer's Disease and Associated Disorders, 6, 77-88.

4. Teresi, J.A., Holmes, D., Dichter, E., Koren, M.J., Ramirez, M., \& Fairchild, S. (1997). Prevalence of behavior disorder and disturbance to family and staff in a sample of adult day health care clients. The Gerontologist, 37, 629-639.

5. Mace M: Principles of activities for persons with dementia. Physical and Occupational Therapy in Geriatrics. 1987; 5: 13-27.

6. Cohen-Mansfield, J., Werner, P., Watson, V., \& Pasis, S. (1995). Agitation in participants of adult day care centers: The experiences of relatives and staff members. International Psychogeriatrics, 7, 447-458.

7. Parmelee P, Lawton M: Handbook of the Psychology of Aging. New York: Academic Press, Inc., 1990.

8. Brandon, L.J., Boyette, L.W., Lloyd, A., \& Gaasch, D.A. (2004). Resistive training and long-term function in older adults. Journal of Aging and Physical Activity, 12, $10-28$.

9. Blumenthal, J.A. \& Gullete, E.C. (2002). Exercise interventions and aging: Psychological and physical health benefits in older adults. In H. Leventhal \& K.W. Schaie (Eds.) Effective Health Behavior in Older Adults. New York, Springer Publishing.

10. Thompson C, Born D: Increasing correct participation in an exercise class for adult day care clients. Behavioral Interventions. 1999; 14: 171-186.

11. Williams P, Lord S: Effects of group exercise on cognitive functioning and mood in older women. Australian and New Zealand Journal of Public Health. 1997; 21: 45-52.

12. Yeung R: The acute effects of exercise on mood state. Journal of Psychosomatic Research. 1996; 4: 123-141.

13. Bonner, A., \& Cousins, S.O. (1996). Exercise and Alzheimer's disease: Benefits and barriers. Activities, Adaptation, \& Aging, 20, 21-34.

14. Beck, C., Modlin, T., Heithoff, K., \& Shue, V. (1992). Exercise as an intervention for behavior problems. Geriatric Nursing, 13, 273-275. 
15. Teri L, Gibbons L, McCurry S, Logsdon R, Buchner D, Barlow W, Kukull W, LaCroix A, McCormick W, Larson E: Exercise plus behavioral management in patients with Alzheimer disease: a randomized controlled trial. JAM. 2003; 290: 2015-22.

16. Femia, E.E. (2004). Effect of ADS on behavior problems of clients with dementa. Contribution to symposium: Effects of Adult Day Services for People with Dementia and their Family Caregivers at the annual meeting of the Gerontological Society of America, Washington, DC.

17. Woods B: Cognitive Neuropsychology of Alzheimer-type Dementia. London: Oxford University Press, 1996.

18. Folstein M, Folstein, S, McHugh P: "Mini Mental State": A practical method for grading the cognitive state of patients for the clinician. Journal of Psychiatric Research. 1975; 12: 189-198.

19. Femia, E. E., Leitsch, S. A., Zarit, S. H., \& Stephens, M. A. P. (July, 2001). Behavior Problems in Dementia: Measurement and comparison of daily and weekly reports. Poster presented at the $17^{\text {th }}$ Congress of the International Association of Gerontology. Vancouver, British Columbia.

20. Leitsch, S.A., Femia, E.E., Zarit, S.H., Greene, R., Stephens, M.A. (2000). Reporting behavior problems: Weekly vs. daily caregiver reports. Poster presented at the annual meeting of the Gerontological Society of America, Washington, DC.

21. Wilson, G.F., Leitsch, S.A., Budinger, K.C., Zarit, S.H., Greene, R., Stephens, M.A., \& Femia, E.E. (2000). Reporting of behavior problems: A comparison of day care and caregiver reports. Poster presented at the annual meeting of the Gerontological Society of America, Washington, DC.

22. Femia, E.E., Leitsch, S.A., Zarit, S.H., \& Stephens, M.P. (2000). Behavior problems in dementia: Measurement and comparison of daily and weekly reports. Poster presented at the annual meeting of the Gerontological Society of America, Washington, DC.

23. Bollen, K. Structural Equation Models. Armitage, P. \& Colton, T. (Eds.) Encyclopedia of Biostatistics (pp. 4363-4372). Sussex: John Wiley, 1998.

24. Muthén L, Muthén B: Mplus Version 2.13. Los Angeles, 2002.

25. Brown M, Cudeck R: Alternative ways of assessing model fit. Sociological Methods and Research, 21, 230-258, 1992.

26. Opie, J., Doyle, C., \& O’Connor, D.W. (2002). Challenging behaviours in nursing home resident with dementia: A randomized controlled trial of multidisciplinary interventions. International Journal of Geriatric Psychiatry, 17, 6-13. 
Table 1: Demographic Characteristics of the Sample

\begin{tabular}{|c|c|c|}
\hline $\mathrm{N}=94$ & CAREGIVER & $\begin{array}{l}\text { PERSON with } \\
\text { DEMENTIA }\end{array}$ \\
\hline $\begin{array}{l}\text { Average Age: mean years } \\
\text { (sd) }\end{array}$ & $59.9(13.4)$ & $79.6(7.5)$ \\
\hline$\%$ Women & $83.0 \%$ & $59.6 \%$ \\
\hline MMSE & N/A & $14.6(6.3)$ \\
\hline $\begin{array}{l}\text { Relationship of Caregiver to } \\
\text { Person with dementia: }\end{array}$ & & \\
\hline Wife & $25.5 \%$ & \\
\hline Husband & $8.5 \%$ & \\
\hline Daughter/Daughter-in- law & $54.3 \%$ & \\
\hline Son/Son-in-law & $8.5 \%$ & \\
\hline Other & $3.2 \%$ & \\
\hline$\%$ Non-white & $14.9 \%$ & $15.9 \%$ \\
\hline$\%$ Employed & $34.0 \%$ & $0.00 \%$ \\
\hline Mean income range & $\$ 40,000-\$ 49,999$ & $\$ 10,000-\$ 19,999 *$ \\
\hline Mean Education: years (sd) & $13.8(2.0)$ & $11.2(2.9)$ \\
\hline Dementia Diagnosis & N/A & $100.00 \%$ \\
\hline
\end{tabular}


Table 2: ADS Categories and Items

\begin{tabular}{|l|l|}
\hline Physical Activities & Formal Exercise \\
& Physical Activity \\
\hline$\underline{\text { Social Activities }}$ & $\begin{array}{l}\text { Parties/Celebrations } \\
\text { Social Hour (coffee) }\end{array}$ \\
\hline$\underline{\text { Engaging Activities }}$ & Discussion Groups (current events, etc.) \\
& Reality Orientation \\
& Singing or Drama Activity \\
& Sitting Game (bingo, etc.) \\
& Arts \& Crafts (sewing, woodwork) \\
\hline$\underline{\text { Watching and Listening Activities }}$ & Visiting Entertainment (pianist, etc.) \\
& TV, Films, or Movies \\
& Religious Services \\
\hline
\end{tabular}

Table 2 shows the individual activity items that were placed in the various activity groups. These items were placed according to inter-rater agreement among 5 trained graduate and undergraduate raters. 
Table 3: Fit Indices for Growth Curve Models

\begin{tabular}{|llll|lll|}
\hline Model & CFI & TLI & RMSEA (L.B., U.B.) & $X^{2}$ & $d f$ & $p$ \\
\hline Restless $^{\mathrm{a}}$ & & & & & & \\
$\quad$-initial model & 1.00 & 1.02 & $0.00(0.00,0.23)$ & 0.38 & 1 & 0.54 \\
$\quad$-with covariates & 0.97 & 0.87 & $0.11(0.00,0.19)$ & 12.19 & 6 & 0.06 \\
$\quad \begin{array}{l}\text { Mood } \\
\quad \text {-initial model }\end{array}$ & 0.99 & 0.99 & $0.04(0.00,0.15)$ & 5.67 & 5 & 0.34 \\
$\quad$-with covariates & 1.00 & 1.03 & $0.00(0.00,0.06)$ & 13.62 & 15 & 0.55 \\
Positive & & & & & & \\
$\quad$-initial model & 0.98 & 0.97 & $0.06(0.00,0.18)$ & 5.23 & 4 & 0.26 \\
-with covariates & 0.97 & 0.93 & $0.05(0.00,0.12)$ & 17.15 & 14 & 0.25 \\
\hline
\end{tabular}

Note: CFI = comparative fit index; TLI = Tucker-Lewis Index; RMSEA = root-meansquare error of approximation; LB, UB = lower and upper bound.

${ }^{\mathrm{a}}$ Quadratic Model. ${ }^{\mathrm{b}}$ Linear Model.

Table 3 shows that the fit for each model was adequate, with fit indices exceeding 0.95 and an RMSEA value less than or equal to 0.05, with the exception of the initial model for positive behaviors (Browne \& Cudeck, 1992). 
Table 4: Summary of Parameter Estimates for Behavior Models

\begin{tabular}{|c|c|c|c|c|c|c|}
\hline & \multicolumn{3}{|c|}{ Fixed Effects } & \multicolumn{3}{|c|}{ Random Effects } \\
\hline & Initial Level & Linear Slope & Quadratic Slope & Initial Level & Linear Slope & Quadratic Slope \\
\hline $\begin{array}{l}\text { Restlessness } \\
\text { (Quadratic Model) }\end{array}$ & $2.68 *(0.09)$ & $0.01(0.04)$ & $0.03(0.03)$ & $0.69 *(0.11)$ & $0.07 *(0.02)$ & $0.03 *(0.02)$ \\
\hline $\begin{array}{l}\text { Mood } \\
\text { (Linear Model) }\end{array}$ & $2.76 *(0.06)$ & $0.00(0.04)$ & -- & $0.28 *(0.05)$ & $0.06 *(0.02)$ & -- \\
\hline $\begin{array}{l}\text { Positive Behaviors } \\
\text { (Linear Model) }\end{array}$ & $4.51 *(0.11)$ & $0.31 *(0.05)$ & -- & $0.72 *(0.14)$ & $-0.02(0.04)$ & -- \\
\hline
\end{tabular}

Note: Standardized errors are shown in parentheses; * indicates a significant estimate at a level of $\mathrm{p}<0.05$ 
Table 5: Summary of Covariate Parameter Estimates for Activities

Physical Activity 23

\begin{tabular}{|c|c|c|c|c|}
\hline & & Restless & Mood & Positive Behaviors \\
\hline Main Model & $\begin{array}{l}\text { Level } \\
\text { L.S. } \\
\text { Q.S. }\end{array}$ & $\begin{array}{l}3.61 *(0.38) \\
-0.16(0.14) \\
0.02(0.13)\end{array}$ & $\begin{array}{c}3.36 *(0.31) \\
-0.12(0.16) \\
--\end{array}$ & $\begin{array}{c}3.13 *(0.41) \\
0.41 *(0.19) \\
--\end{array}$ \\
\hline $\begin{array}{l}\text { Physical } \\
\text { Activities } \\
\text { Group }\end{array}$ & $\begin{array}{l}\text { Level } \\
\text { L.S. } \\
\text { Q.S. }\end{array}$ & $\begin{array}{l}-0.19(0.11) \\
0.04(0.04) \\
0.02(0.04)\end{array}$ & $\begin{array}{c}-0.08(0.09) \\
0.03(0.05) \\
--\end{array}$ & $\begin{array}{c}0.17(0.12) \\
0.02(0.06) \\
--\end{array}$ \\
\hline $\begin{array}{l}\text { Social } \\
\text { Activities } \\
\text { Group }\end{array}$ & $\begin{array}{l}\text { Level } \\
\text { L.S. } \\
\text { Q.S. }\end{array}$ & $\begin{array}{l}0.04(0.12) \\
0.08(0.04) \\
-0.02(0.04)\end{array}$ & $\begin{array}{c}0.01(0.10) \\
0.06(0.05) \\
--\end{array}$ & $\begin{array}{c}0.27 *(0.13) \\
-0.09(0.06) \\
--\end{array}$ \\
\hline $\begin{array}{l}\text { Engaging } \\
\text { Activities } \\
\text { Group }\end{array}$ & $\begin{array}{l}\text { Level } \\
\text { L.S. } \\
\text { Q.S. }\end{array}$ & $\begin{array}{l}-0.04(0.13) \\
-0.11 *(0.04) \\
-0.02(0.04)\end{array}$ & $\begin{array}{c}-0.01(0.11) \\
-0.08(0.06) \\
--\end{array}$ & $\begin{array}{c}0.20(0.14) \\
0.11(0.07) \\
--\end{array}$ \\
\hline $\begin{array}{l}\text { W \& L } \\
\text { Activities } \\
\text { Group }\end{array}$ & $\begin{array}{l}\text { Level } \\
\text { L.S. } \\
\text { Q.S. }\end{array}$ & $\begin{array}{l}-0.19(0.12) \\
-0.06(0.04) \\
0.00(0.04)\end{array}$ & $\begin{array}{c}-0.05(0.09) \\
-0.07(0.05) \\
--\end{array}$ & $\begin{array}{c}-0.07(0.12) \\
-0.05(0.06) \\
--\end{array}$ \\
\hline $\begin{array}{l}\text { Day Care } \\
\text { Dosage } \\
\text { Variable }\end{array}$ & $\begin{array}{l}\text { Level } \\
\text { L.S. } \\
\text { Q.S. }\end{array}$ & $\begin{array}{l}-0.10(0.11) \\
0.13 *(0.04) \\
0.02(0.04)\end{array}$ & $\begin{array}{c}-0.17(0.09) \\
0.11 *(0.04) \\
--\end{array}$ & $\begin{array}{c}0.11(0.13) \\
-0.04(0.05) \\
--\end{array}$ \\
\hline
\end{tabular}

Note: Standardized errors are shown in parentheses; * indicates a significant estimate at a level of $p<0.05$ 
Figure 1: A Sub-section of the Daily Record of Behavior Form

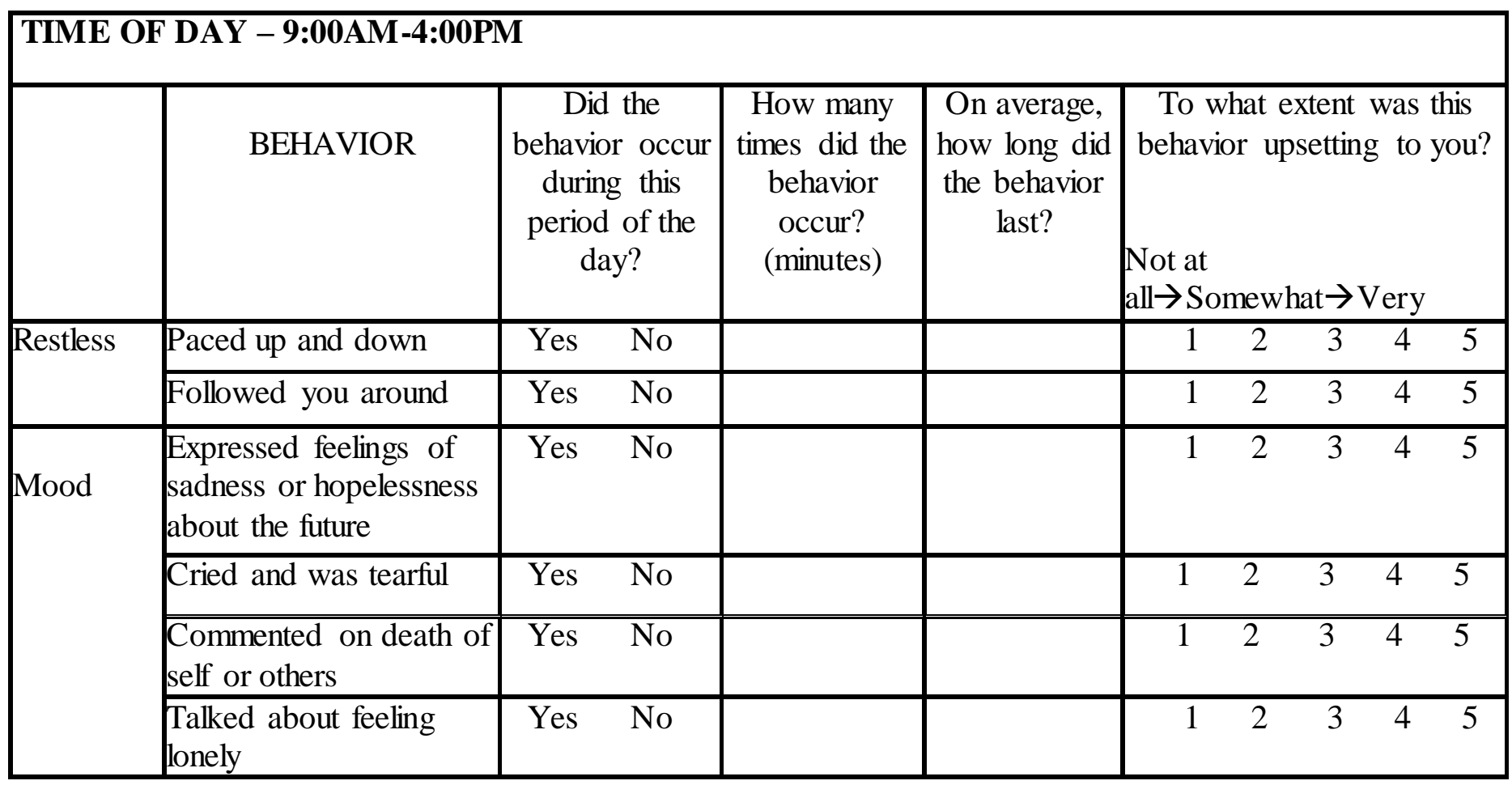

